\title{
Expression of the TGF- $\beta$ Family of Ligands Is Developmentally Regulated in Skeletal Muscle of Neonatal Rats
}

\author{
AGUS SURYAWAN, JASON W. FRANK, HANH V. NGUYEN, AND TERESA A. DAVIS \\ Department of Pediatrics, USDA/ARS Children's Nutrition Research Center, Baylor College of Medicine, Houston, Texas 77030
}

\begin{abstract}
To dissect the possible role of the transforming growth factor- $\beta$ (TGF- $\beta$ ) family in the regulation of skeletal muscle growth during the early postnatal period, the protein abundances of the TGF- $\beta$ family and their correlation with protein synthesis were determined in skeletal muscle of neonatal rats. To obtain direct evidence of the role of these growth factors in the regulation of protein synthesis, the TGF- $\beta$ inhibitor, follistatin, was infused into 10 -d-old rats for $11 \mathrm{~d}$ and protein synthesis and phosphorylation of S6 kinase 1 (S6K1) and ribosomal protein (rpS6) were measured. TGF- $\beta 2$ abundance and protein synthesis in muscle decreased with development and were positively correlated. The abundances of bone morphogenetic protein 2 (BMP-2), BMP-7, and myostatin increased with development and were negatively correlated with protein synthesis. The abundances of BMP-2 and BMP-7 were positively correlated with BMP receptor IA (BMP-RIA) abundance. Activin A abundance was positively correlated with follistatin abundance and activin receptor IIB (Act-RIIB) abundance. Infusion of follistatin increased muscle protein synthesis and S6K1 and rpS6 phosphorylation. The results provide indirect and direct evidence of TGF- $\beta$ family involvement in the regulation of muscle protein synthesis during the neonatal period. (Pediatr Res 59: 175-179, 2006)
\end{abstract}

$\mathbf{I}^{\mathrm{t}}$ $t$ is well recognized that, during the neonatal period, rates of growth and protein turnover are very high (1). Furthermore, a more rapid gain in protein mass occurs in skeletal muscle than in the body as a whole (2). This high rate of muscle protein deposition is largely driven by the high fractional rate of protein synthesis in skeletal muscle (3). Using animal models, we have demonstrated that the fractional rate of protein synthesis in skeletal muscle is very high immediately after birth, and about $50 \%$ of the decline in protein synthesis occurs during the first $3 \mathrm{wk}$ of life (4).

A number of studies have shown that skeletal muscle protein synthesis in growing animals is both acutely and chronically sensitive to hormonal stimuli (5). Our studies using neonatal pigs indicate that an enhanced sensitivity to insulin and IGF-I contributes to the high rate of skeletal muscle protein synthesis and muscle growth in neonates and this effect declines with development $(6,7)$. Although the TGF- $\beta$ family of ligands has also been implicated in the

Received June 21, 2005; accepted September 16, 2005.

Correspondence: Agus Suryawan, Ph.D., USDA/ARS Children's Nutrition Research Center, Department of Pediatrics, Baylor College of Medicine, 1100 Bates St., Houston, TX 77030-2600; e-mail: suryawan@bcm.tmc.edu

Supported by funds from the National Institutes of Health Research Grant RO1AR44474, USDA/ARS under Cooperative Agreement no-58-6250-6-001 and The Bristol Myers Squibb/Mead Johnson Unrestricted Research Grant: Pilot Project Program.

DOI: 10.1203/01.pdr.0000196718.47935.6e regulation of skeletal muscle growth in embryos and mature animals $(8,9)$, the possible role of these growth factors in skeletal muscle growth during the neonatal period remains poorly understood.

TGF- $\beta 2$, a positive regulator of skeletal muscle growth in vivo (10), regulates when and where myoblasts fuse to myotubes and is expressed at high levels on embryonic d 14, at lower levels by postnatal d 3, and at negligible levels in adult muscle (10). Follistatin, another positive regulator of skeletal muscle growth, has been shown to be essential for normal development (11). Mice with a null mutation of follistatin die soon after birth with a range of defects including insufficient muscle development and skeletal abnormalities (11) and mice that overexpress follistatin exhibit a dramatic increase in skeletal muscle mass (12). Follistatin has been shown to neutralize the inhibitory action of activin, BMP-2, and myostatin on muscle growth by binding to these ligands, and thereby preventing the activation of their receptors (13).

Activin A, BMP-2, BMP-7, and myostatin are classified as negative regulators of skeletal muscle growth. Activin A is a growth and differentiation factor that is involved in many physiologic processes in a variety of tissues including skeletal muscle (14). Activin A has been found to inhibit myotube growth in cell culture (15). BMP-2 and BMP-7 are members of the TGF- $\beta$ superfamily that induce bone and cartilage formation (16) and inhibit muscle growth (17). Likewise, myostatin (growth differentiation factor-8) has been shown to negatively regulate skeletal muscle growth in mice and humans (18). In C2C12 muscle cell cultures, myostatin inhibits myoblast proliferation and differentiation, in part due to a myostatin-induced reduction in protein synthesis (19).

The effects of TGF- $\beta$ are mediated through Smaddependent and Smad-independent pathways (20). In the Smad-independent pathway, the binding of TGF- $\beta$ to its receptor induces an interaction between $\mathrm{PP} 2 \mathrm{~A}-\mathrm{B} \alpha$ and the TGF- $\beta$ receptor I (TGF- $\beta$ RI), resulting in the activation of the PP2A complex and subsequent dephosphorylation and inactivation of S6K1 (20). S6K1, a major protein kinase involved in

\footnotetext{
Abbreviations: Act-RIIB, activin receptor IIB; BMP, bone morphogenetic protein; BMP-RIA, bone morphogenetic protein receptor IA; PP2A, protein phosphatase 2A; rpS6, ribosomal protein S6; S6K1, S6 kinase 1; TGF- $\boldsymbol{\beta}$, transforming growth factor beta
} 
translation initiation, is known to phosphorylate and activate ribosomal protein S6 (rpS6) (21), resulting in a selective increase in translation of mRNA containing a terminus of polypyrimidine tracts (TOP). These mRNA encode for proteins of the translational apparatus such as elongation factors and ribosomal proteins (22).

In the present study, we addressed the question as to whether the TGF- $\beta$ family of ligands is involved in modulating skeletal muscle growth during the neonatal period. We investigated the protein abundances of the TGF- $\beta$ family and their relationships with protein synthesis in skeletal muscle of neonatal rats. The results of this study suggest that the TGF- $\beta$ family of ligands and their binding protein are important regulators of protein synthesis, and thus skeletal muscle growth, in neonates.

\section{MATERIALS AND METHODS}

Animals and study design. Pregnant Sprague-Dawley rats (Harlan Bioproducts for Science, Indianapolis, IN) were housed individually in woodchip bedded cages at constant temperature $\left(74^{\circ} \mathrm{F}\right)$ and humidity $(60 \pm 5 \%)$ with a 12-h light/dark cycle. They had free access to water and a commercial $\operatorname{diet}$ (Purina, St. Louis, MO). After birth, the pups were allowed to suckle their dams. Within $1 \mathrm{~d}$ of birth, litters were adjusted to a size of 10, with equal numbers of males and females within each litter. At d 1, 5, 10, 16, 21, and 28, the rats were killed. Before euthanasia, the rats were fasted for $4 \mathrm{~h}$ and then they were returned to their dams for $1 \mathrm{~h}$ (suckling period). At the end of suckling period, rats were given an intraperitoneal (i.p.) injection of L[4${ }^{3} \mathrm{H}$ ]phenylalanine and euthanized 10 min later. A group of muscles that contain primarily fast-twitch muscle fibers (quadriceps, gastrocnemius, extensor digitorum longus/EDL and anterior tibialis/AT) from one hind limb from each rat was dissected, pooled, and homogenized (Western blot analysis). Muscles from the other hind limb from each rat were stored at $-70^{\circ} \mathrm{C}$ for later determination of fractional protein synthesis rate.

To study the biologic effects of follistatin, $1 \mu \mathrm{g} / \mathrm{d}$ recombinant Follistatin288 (R \& D Systems, Minneapolis, MN) was continuously infused for $11 \mathrm{~d}$ using osmotic pumps (Alzet, Cupertino, CA) beginning at $10 \mathrm{~d}$ of age. The control rats were implanted with mini-pumps containing vehicle (PBS). At the end of the experiment, rats were killed and the muscle was harvested and analyzed for translation initiation factor activation and fractional protein synthesis rate. The protocol was approved by the Animal Care and Use Committee of Baylor College of Medicine and was conducted in accordance with the National Research Council's Guide for the Care and Use of Laboratory Animals.

Materials. Reagents for SDS-PAGE were from Bio-Rad Laboratories (Richmond, CA). The protein assay kit was purchased from Pierce (Rockford, IL). Activin A, Act-RIIB, BMP-2, BMP-7, BMP-RIA, follistatin, and TGF- $\beta 2$ antibodies as well as recombinant follistatin were purchased from $\mathrm{R}$ \& D Systems. Myostatin antibody was purchased from Orbigen (San Diego, CA). S6K1 and rpS6 specific antibodies that recognize phospho-S6K1 and phopho-rpS6 as well as total S6K1 and rpS6 were purchased from Cell Signaling Technology (Beverly, MA). The enhanced chemiluminescence Western blotting detection kit (ECL-Plus) was obtained from Amersham Biosciences (Arlington Heights, IL). Other chemicals and reagents were from Sigma Chemical Co. (St. Louis, MO).

Tissue protein synthesis in vivo. Fractional rates of protein synthesis were measured with a flooding dose of L- $\left[4-{ }^{3} \mathrm{H}\right]$ phenylalanine (Amersham Biosciences, Piscataway, NJ) (4). Rats were euthanized 10 min after i.p. injection of L-[4- $\left.{ }^{3} \mathrm{H}\right]$ phenylalanine, and muscle samples were collected and immediately frozen in liquid nitrogen and stored at $-70^{\circ} \mathrm{C}$ until analyzed. Phenylalanine from homogenate was separated from other amino acids by anion exchange chromatography (PA1 column, Dionex, Sunnyvale, CA) as described previously (4). Fractions were collected and the radioactivity associated with the phenylalanine peak was measured using ScintiVerse II (Fisher Scientific, Pittsburgh, PA) in a liquid scintillation counter (TM Analytic, Elk Grove Village, IL). Protein synthesis $\left(K_{\mathrm{s}}\right.$ expressed as $\%$ protein synthesized in a day) was calculated as: $K_{\mathrm{s}}(\% / \mathrm{d})=\left[\left(\mathrm{S}_{\mathrm{b}} / \mathrm{S}_{\mathrm{a}}\right) \times(1,440 / t)\right] \times 100$, where $\mathrm{S}_{\mathrm{b}}$ is the specific radioactivity of the protein-bound phenylalanine; $\mathrm{S}_{\mathrm{a}}$ is the specific radioactivity of the tissue free phenylalanine for the labeling period, determined from the value of the animal at the time of tissue collection, corrected by the linear regression of the blood specific radioactivity of the animal against time; and $t$ is the time of labeling in minutes.

Western blot analysis. Equal amounts of protein samples were separated on SDS-PAGE and transferred to a polyvinylidene difluoride transfer membrane (Bio-Rad) as previously described (23). The membrane was incubated with primary antibody overnight followed by a 1-h incubation with secondary antibody. The membrane was then washed with Tris-buffered saline-Tween 20 solution. Blots were developed using an enhanced chemiluminescence Western blotting kit (ECL-plus, Amersham), visualized using a ChemiDoc-It imaging system (UVP, Inc., Upland, CA).

Measurement of site-specific phosphorylation of S6K1 and rpS6. Phosphorylation of S6K1 and rpS6 was determined by Western blot analysis (24) using antibodies that recognize S6K1 when it is phosphorylated at $\mathrm{Thr}^{389}$, and rpS6 when it is phosphorylated at $\operatorname{Ser}^{235 / 236}$ and $\operatorname{Ser}^{240 / 244}$. The membranes were then stripped and reprobed with an S6K1 or rpS6 antibody that recognizes both the phosphorylated and unphosphorylated forms of the proteins. Values obtained using the anti-phospho-S6K1 or rpS6 antibody were normalized for the total amount of S6K1 or rpS6 present in the samples.

Statistics. ANOVA was used to assess the effect of age on fractional protein synthesis rate and the protein abundances of the TGF- $\beta$ family. Tukey multiple comparison test was used to test for differences between groups. The relationship between protein synthesis and growth factor abundance was determined by correlation analysis. Probability values of $p<0.05$ were considered statistically significant. Data are presented as means \pm SE.

\section{RESULTS}

Muscle protein synthesis rate and the abundance of TGF$\beta 2, B M P-2, B M P-7$, and myostatin during the neonatal period. The results from the current study showed that the fractional rate of muscle protein synthesis decreased with development $(p<0.05$; Fig. $1 A)$. The reduction in the rate of skeletal muscle protein synthesis was $65 \%$ over the first $4 \mathrm{wk}$ of postnatal life (Fig. 1A). Interestingly, the abundance of TGF- $\beta 2$ in skeletal muscle decreased by $85 \%$ during the same period $(p<0.05$; Fig. $1 B$ ). There was a positive correlation $(r=0.89 ; p<0.001$; Fig. $1 C)$ between TGF- $\beta 2$ abundance and the rate of protein synthesis in skeletal muscle during the neonatal period.

Unlike the abundance of TGF- $\beta 2$, the abundances of BMP-2, BMP-7, and myostatin in skeletal muscle increased $(p<0.05)$ with development (Fig. 2, $A$ and $C$, Fig. 3A). There were negative correlations between muscle protein synthesis rate and the abundance of BMP-2 $(r=-0.91 ; p<0.001$;

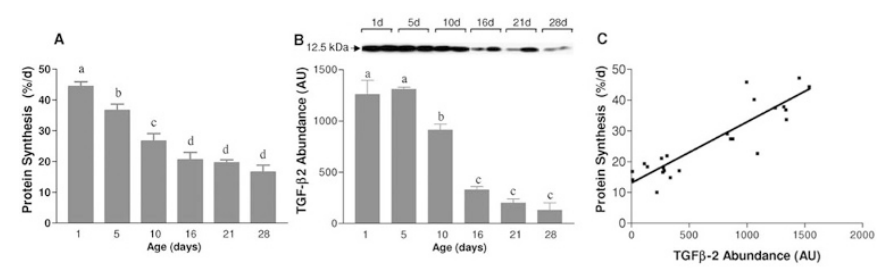

Figure 1. The fractional rate of protein synthesis, TGF- $\beta 2$ abundance, and the correlation between protein synthesis and TGF- $\beta 2$ abundance in skeletal muscle of neonatal rats. (A) Fractional rates of protein synthesis were determined using the flooding-dose technique. The rate of protein synthesis decreased significantly with development $(p<0.05)$. (B) To determine TGF- $\beta 2$ protein abundance, equal amounts of protein samples were subjected to SDS-PAGE followed by immunoblot analysis with anti-TGF- $\beta 2$. Representative Western blots are shown above the graph. TGF- $\beta 2$ protein abundance decreased significantly with development $(p<0.05)$. (C) The relationship between the rate of protein synthesis and TGF- $\beta 2$ abundance was determined by correlation analysis. The rate of protein synthesis was positively correlated with TGF- $\beta 2$ abundance $(r=0.89, p<0.001)$. Western blot results are in arbitrary units (AU). Values are means \pm SE, $n=4$. Means without a common letter differ, $p<0.05$. 
Fig. 2B), BMP-7 $(r=-0.81 ; p<0.001$; Fig. $2 D)$ and myostatin $(r=-0.85 ; p<0.001 ;$ Fig. $3 B)$ during the neonatal period.

Activin $A$ and follistatin abundance in skeletal muscle during the neonatal period. The protein abundance of both activin and follistatin in muscle significantly increased $(p<$ 0.05 ) from birth to $10 \mathrm{~d}$ of age and then declined (Fig. 4, $A$ and $B)$. There was no correlation between muscle protein synthesis rate and the abundances of either activin A or follistatin. However, there was a positive correlation between activin A abundance and follistatin abundance $(r=0.91 ; p<0.001$; Fig. 4C).

BMP-RIA and Act-RIIB abundance in skeletal muscle during the neonatal period. The abundance of the BMP-RIA increased $(p<0.05)$ with development (Fig. 5A). There were positive correlations between BMP-RIA abundance and the abundance of BMP-2 $(r=0.81, p<0.001$; Fig. $5 B)$ and BMP-7 ( $r=0.72 ; p<0.001$; Fig. $5 C$ ). The results also showed that the abundance of Act-RIIB peaked at d 10 and decreased thereafter $(p<0.05$; Fig. $6 A)$. There was a positive correlation between Act-RIIB abundance and activin A abundance $(r=0.91 ; p<0.001$; Fig. $6 B)$.

Administration of recombinant follistatin stimulates muscle protein synthesis through activation of S6K1 and rpS6. The recombinant proteins of the TGF- $\beta$ family have been administrated locally or systemically in animal models (25). To take advantage of this approach, we continuously infused recombinant follistatin for $11 \mathrm{~d}$ using mini pumps that were implanted subcutaneously into 10 -d-old neonatal rats. The
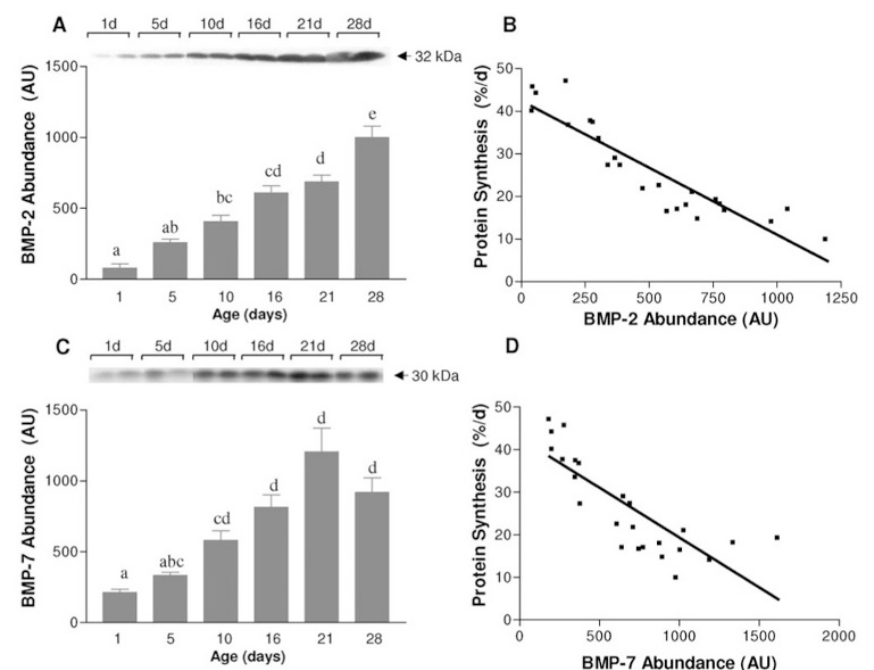

D

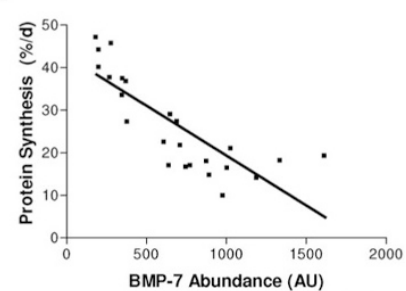

Figure 2. BMP-2 and BMP-7 protein abundances and their correlation with protein synthesis in skeletal muscle of neonatal rats. To determine BMP-2 and BMP-7 protein abundances, equal amounts of protein samples were subjected to SDS-PAGE followed by immunoblot analysis with anti-BMP-2 or BMP-7. Representative Western blots are shown above each graph. The BMP-2 protein abundance $(A)$ as well as BMP-7 abundance $(C)$ increased significantly with development $(p<0.001)$. The relationships between the rate of protein synthesis and BMP-2 or BMP-7 abundances were determined by correlation analysis. The rate of protein synthesis was inversely correlated with BMP-2 abundance $(r=0.91, p<0.001)(B)$ as well as with BMP-7 abundance $(r=0.81, p<0.001)(D)$. Western blot results are in arbitrary units (AU). Values are means $\pm \mathrm{SE}, n=4$. Means without a common letter differ, $p<0.05$.
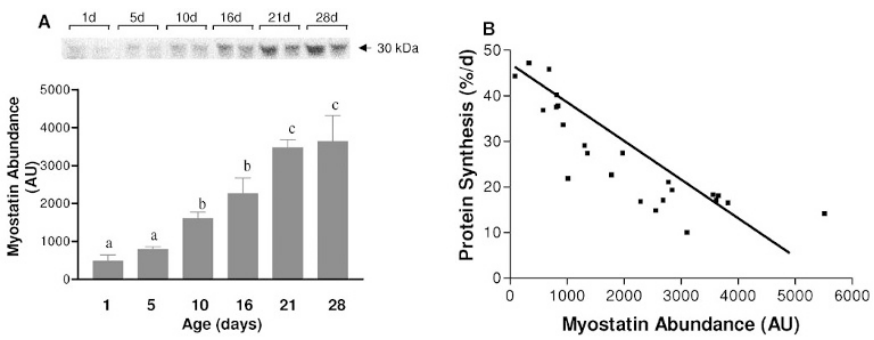

Figure 3. Myostatin protein abundance and its correlation with protein synthesis in skeletal muscle of neonatal rats. (A) To determine myostatin protein abundance, equal amounts of protein samples were subjected to SDS-PAGE followed by immunoblot analysis with anti-myostatin. Representative Western blots are shown above the graph. Myostatin protein abundance increased significantly with development $(p<0.001)$. (B) The relationships between the rate of protein synthesis and myostatin abundance was determined by correlation analysis. The rate of protein synthesis was inversely correlated with myostatin abundance $(r=-0.85, p<0.001)$. Western blot results are in arbitrary units (AU). Values are means $\pm \mathrm{SE}, n=4$. Means without a common letter differ, $p<0.05$.

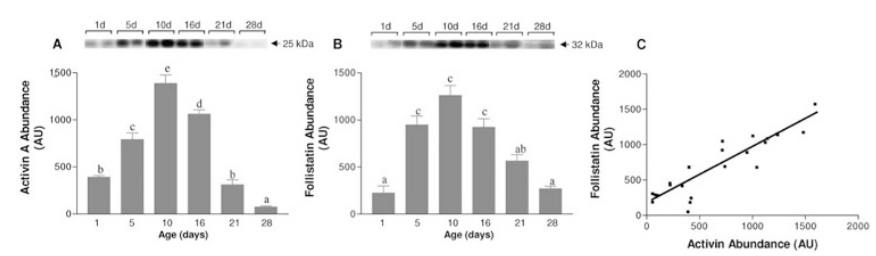

Figure 4. Activin-A and follistatin protein abundances and their correlation in skeletal muscle of neonatal rats. To determine activin-A and follistatin protein abundance, equal amounts of protein samples were subjected to SDS-PAGE followed by immunoblot analysis with anti-activin-A or follistatin. Representative Western blots are shown above each graph. Activin A protein abundance $(A)$ as well as follistatin protein abundance $(B)$ changed with development $(p<0.001)$. $(C)$ The relationship between activin-A and follistatin abundance was determined by correlation analysis. The activin-A abundance was positively correlated with follistatin abundance $(r=0.90, p<$ $0.001)$. Western blot results are in arbitrary units (AU). Values are means \pm $\mathrm{SE}, n=4$. Means without a common letter differ, $p<0.05$.

result showed (Fig. 7A) that infusion of recombinant follistatin into neonatal rats stimulated protein synthesis in skeletal muscle by approximately $20 \%(p<0.05)$. Although follistatin infusion induced an increase in muscle protein synthesis, the body weights of follistatin-infused rats were not significantly different from control rats (data not shown). This is probably due to the short length of infusion.

S6K1 and rpS6 are major signaling components that regulate translation initiation, and thus protein synthesis, in skeletal muscle $(21,22)$. We determined the effect of infusion of recombinant follistatin on S6K1 and rpS6 phosphorylation. The results showed that, similar to follistatin-induced muscle protein synthesis (Fig. 7A), infusion of recombinant follistatin stimulated S6K1 and rpS6 phosphorylation ( $p<0.05$; Fig. 7, $B$ and $C$ ).

\section{DISCUSSION}

The role of the TGF- $\beta$ family of ligands and their binding protein as positive or negative regulators of muscle growth in cell cultures, embryos, and adult animals has been well established $(8,9)$. However, until now, the possible role of the 


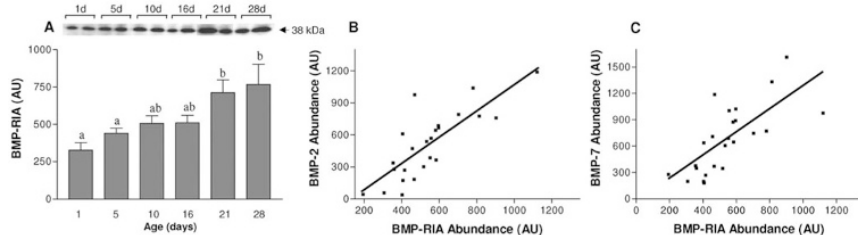

Figure 5. The abundance of BMP-RIA and its correlation with BMP-2 or with BMP-7 abundances in skeletal muscle of neonatal rats. (A) To determine BMP-RIA protein abundance, equal amounts of protein samples were subjected to SDS-PAGE followed by immunoblot analysis with anti-BMP-RIA. Representative Western blots are shown above the graph. BMP-RIA protein abundance increased significantly with development $(p<0.001)$. The relationships between BMP-RIA and BMP-2 or BMP-7 abundances were determined by correlation analysis. BMP-RIA abundance was positively correlated with BMP-2 abundance $(r=0.81, p<0.001)(B)$ as well as with BMP-7 abundance $(r=0.72, p<0.001)(C)$. Western blot results are in arbitrary units (AU). Values are means $\pm \mathrm{SE}, n=4$. Means without a common letter differ, $p<0.05$.
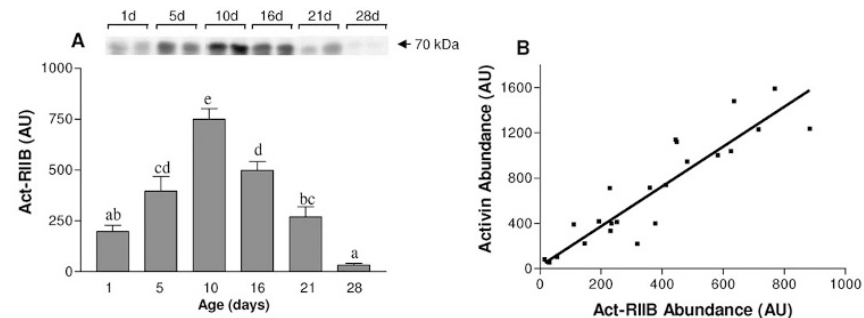

Figure 6. The abundance of Act-RIIB and its correlation with activin-A abundance in skeletal muscle of neonatal rats. (A) To determine Act-RIIB protein abundance, equal amounts of protein samples were subjected to SDS-PAGE followed by immunoblot analysis with anti-Act-RIIB. Representative Western blots are shown above the graph. Act-RIIB protein abundance changed with development $(p<0.001)$. $(B)$ The relationship between ActRIIB and activin abundance was determined by correlation analysis. Act-RIIB abundance was positively correlated with activin abundance $(r=0.91, p<$ $0.001)$. Western blot results are in arbitrary units (AU). Values are means \pm $\mathrm{SE}, n=4$. Means without a common letter differ, $p<0.05$.

TGF- $\beta$ family of ligands and their binding protein in the regulation of skeletal muscle growth in neonates has not been studied. Here we show that the protein abundance of the TGF- $\beta$ family of ligands and their binding protein in skeletal muscle changes during early postnatal development and that the abundances of these growth factors are correlated with the changes in muscle protein synthesis, suggesting indirectly their function as regulators of muscle growth in neonates.

Supporting the idea that TGF- $\beta 2$ acts as a positive regulator of muscle growth (26), we found that the protein abundance of TGF- $\beta 2$ decreases with development. This observation is consistent with the results of Koishi et al. (10), who found that the mRNA level of TGF- $\beta 2$ is high on embryonic d 14 , reduced by d 3 postnatal age, and negligible in adult rats. Our results also showed a positive correlation between the rate of skeletal muscle protein synthesis and TGF- $\beta 2$ abundance, indirectly indicating the involvement of TGF- $\beta 2$ in supporting the high rate of muscle growth during the early neonatal period.

In vivo and in vitro studies indicate that BMP-2, BMP-7, and myostatin inhibit muscle growth $(8,9,17)$. The results of a recent cell culture study suggest that myostatin inhibits growth
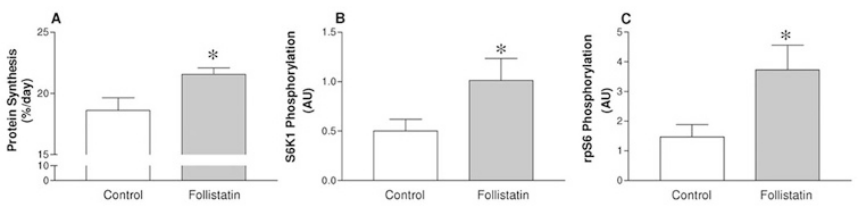

Figure 7. Effect of chronic follistatin infusion on protein synthesis and the phosphorylation of S6K1 and rpS6 in skeletal muscle of neonatal rats. (A) The fractional rate of protein synthesis was determined using the flooding-dose technique. S6K1 phosphorylation on $\mathrm{Thr}^{389}(B)$ and $\mathrm{rpS} 6$ phosphorylation on $\operatorname{Ser}^{235 / 236}$ and $\operatorname{Ser}^{240 / 244}(C)$ were measured by Western blot analysis using antibodies that recognize S6K1 only when Thr389 is phosphorylated or using antibodies that recognize rpS6 only when $\operatorname{Ser}^{235 / 236}$ and $\operatorname{Ser}^{240 / 244}$ are phosphorylated. Representative Western blots are shown above each graph. Results were normalized for S6K1 and rpS6 content, respectively. Western blot results are in arbitrary units (AU). Values represent means \pm SE in arbitrary units (five animals per group).

by inhibiting protein synthesis (19). Consistent with their role as negative regulators of muscle growth, our results show that the protein abundance of BMP-2, BMP-7, and myostatin increases with development in skeletal muscle of neonatal rats and is negatively correlated with protein synthesis. Among these negative regulators of muscle growth, myostatin is the most studied (27). Recently, Escobar et al. (28) found a negative correlation between the weight of pig skeletal muscle and myostatin mRNA abundance.

In recent in vivo studies, activin $\mathrm{A}$ and follistatin were found to be necessary for normal skeletal muscle development (29). Accordingly, our results demonstrate that the protein abundance of activin A and follistatin in skeletal muscle changes with development. More importantly, the pattern of expression of both proteins was similar, consistent with the function of follistatin as an activin A binding protein. Accumulated evidence indicates that follistatin binds activin $\mathrm{A}$ and neutralizes activin A action (30). These results support the idea that during the neonatal period, follistatin acts to blunt the inhibitory effect of activin A on skeletal muscle growth.

Cell-surface receptors, such as Act-RIIB or BMP-RIA, are important for transmitting the biologic effects of the TGF- $\beta$ family (31). Our results show that the protein abundance of BMP-RIA, the specific receptor for BMP-2 and BMP-7, increases with development. Our results also show that there is a high positive correlation between the BMP-RIA abundance and the abundance of both BMP-2 and BMP-7, which is indirectly suggestive that both BMP-2 and BMP-7 have biologic functions in the development of skeletal muscle in neonatal rats. Similarly, a high positive correlation of the abundance of Act-RIIB with the abundance of activin A indirectly indicates that activin A is necessary to the development of skeletal muscle in neonatal rats and that that its action is elicited by this receptor.

The correlation between the rates of protein synthesis and abundance of individual members of the TGF- $\beta$ family in skeletal muscle is suggestive that these ligands are regulators of muscle protein synthesis during early postnatal development. However, to obtain more direct evidence, we chose to test whether protein synthesis rates in muscle could be altered by changing the circulating level of one of the TGF- $\beta$ family members. We infused follistatin because follistatin has been 
shown to bind and neutralize the inhibitory effects of BMP-2, BMP-7, and myostatin (13). The rationale of this study was that by infusing follistatin from 10 to $21 \mathrm{~d}$ of age, when the protein abundance of BMP-2, BMP-7, and myostatin is high, their inhibitory effects on protein synthesis could be suppressed. Our results did indeed show that chronic follistatin infusion stimulated protein synthesis in skeletal muscle of neonatal rats and that it did so by increasing the phosphorylation of the translation initiation factors, S6K1 and rpS6. Interestingly, one of the mechanisms by which myostatin has been shown to inhibit muscle cell growth is by suppressing protein synthesis (19). Therefore, an increase in muscle protein synthesis in follistatin-infused rats is consistent with the notion that follistatin blunts myostatin action (12).

Follistatin also binds and neutralizes the activation of growth/differentiation factor (GDF)-11 (32). GDF-11 does not appear to be a regulator of muscle growth. Using GDF-11 knockout mice, McPherron et al. (33) found that GDF-11 regulates anterior/posterior pattering of axial skeleton without affecting muscle growth. Therefore, in our follistatin study, it is unlikely that GDF-11 is involved in stimulating muscle protein synthesis.

In conclusion, the results of our study suggest that the TGF- $\beta$ family of ligands and their binding protein play an important role in the regulation of protein synthesis in skeletal muscle of neonatal rats. Our ongoing studies are focused toward understanding in vivo signaling events, and particularly the cross-talk between the TGF- $\beta$ signaling pathway and the translation initiation pathway. Our studies elucidating the novel role of the TGF- $\beta$ family of ligands and their binding protein in regulating skeletal muscle growth in neonatal rats may provide important new importation for the development of strategies to enhance skeletal muscle growth in neonates.

Acknowledgments. The authors thank William Liu and Marie Ng for laboratory assistance, Jerome Stubblefield for care of animals, and Linda Weiser for secretarial assistance.

\section{REFERENCES}

1. Denne SC, Kalhan SC 1987 Leucine metabolism in human newborns. Am J Physiol 253:E608-E615

2. Young VR 1970 The role of skeletal and cardiac muscle in the regulation of protein metabolism. In: Munro HN (ed) Mammalian Protein Metabolism. Academic, New York, pp 585-674

3. Davis TA, Fiorotto ML 2005 Regulation of skeletal muscle protein metabolism in growing animals. In: Burrin DG, Mersmann HJ (eds) Biology of Metabolism in Growing Animals. Elsevier, New York, pp 37-67

4. Davis TA, Fiorotto ML, Nguyen HV, Reeds PJ 1989 Protein turnover in skeletal muscle of suckling rats. Am J Physiol 257:R1141-R1146

5. Waterlow JC, Golden MH, Garlick PJ 1978 Protein turnover in man measured with 15N: comparison of end products and dose regimes. Am J Physiol 235:E165-E174

6. Davis TA, Fiorotto ML, Burrin DG, Vann RC, Reeds PJ, Nguyen HV, Beckett PR, Bush JA 2002 Acute IGF-I infusion stimulates protein synthesis in skeletal muscle and other tissues of neonatal pigs. Am J Physiol 283:E638-E647
7. Davis TA, Fiorotto ML, Burrin DG, Reeds PJ, Nguyen HV, Beckett PR, Vann RC, O'Connor PM 2002 Stimulation of protein synthesis by both insulin and amino acids is unique to skeletal muscle in neonatal pigs. Am J Physiol Endocrinol Metab 282:E880-E890

8. Amthor H, Christ B, Rashid-Doubell F, Kemp CF, Lang E, Patel K 2002 Follistatin regulates bone morphogenetic protein-7 (BMP-7) activity to stimulate embryonic muscle growth. Dev Biol 243:115-127

9. McPherron AC, Lawler AM, Lee SJ 1997 Regulation of skeletal muscle mass in mice by a new TGF-beta superfamily member. Nature 387:83-90

10. Koishi K, Dalzell KG, McLennan IS 2000 The expression and structure of TGFbeta2 transcripts in rat muscles. Biochim Biophys Acta 1492:311-319

11. Matzuk MM, Lu N, Vogel H, Sellheyer K, Roop DR, Bradley A 1995 Multiple defects and perinatal death in mice deficient in follistatin. Nature 374:360-363

12. Lee SJ, McPherron AC 2001 Regulation of myostatin activity and muscle growth. Proc Natl Acad Sci U S A 98:9306-9311

13. Amthor H, Nicholas G, McKinnell I, Kemp CF, Sharma M, Kambadur R, Patel K 2004 Follistatin complexes Myostatin and antagonises Myostatin-mediated inhibition of myogenesis. Dev Biol 270:19-30

14. Mathews LS 1994 Activin receptors and cellular signaling by the receptor serine kinase family. Endocr Rev 15:310-325

15. Link BA, Nishi R 1997 Opposing effects of activin A and follistatin on developing skeletal muscle cells. Exp Cell Res 233:350-362

16. Ebara S, Nakayama K 2002 Mechanism for the action of bone morphogenetic proteins and regulation of their activity. Spine 27:S10-S15

17. Inada M, Katagiri T, Akiyama S, Namika M, Komaki M, Yamaguchi A, Kamoi K, Rosen V, Suda T 1996 Bone morphogenetic protein-12 and -13 inhibit terminal differentiation of myoblasts, but do not induce their differentiation into osteoblasts. Biochem Biophys Res Commun 222:317-322

18. Whittemore LA, Song K, Li X, Aghajanian J, Davies M, Girgenrath S, Hill JJ, Jalenak M, Kelley P, Knight A, Maylor R, O'Hara D, Pearson A, Quazi A, Ryerson S, Tan XY, Tomkinson KN, Veldman GM, Widom A, Wright JF, Wudyka S, Zhao L, Wolfman NM 2003 Inhibition of myostatin in adult mice increases skeletal muscle mass and strength. Biochem Biophys Res Commun 300:965-971

19. Taylor WE, Bhasin S, Artaza J, Byhower F, Azam M, Willard Jr, DH Kull Jr, FC Gonzalez-Cadavid N 2001 Myostatin inhibits cell proliferation and protein synthesis in C2C12 muscle cells. Am J Physiol Endocrinol Metab 280:E221-E228

20. Petritsch C, Beug H, Balmain A, Oft M 2000 TGF-beta inhibits p70 S6 kinase via protein phosphatase 2A to induce G(1) arrest. Genes Dev 14:3093-3101

21. Dufner A, Thomas G 1999 Ribosomal S6 kinase signaling and the control of translation. Exp Cell Res 253:100-109

22. Jefferies HB, Fumagalli S, Dennis PB, Reinhard C, Pearson RB, Thomas G 1997 Rapamycin suppresses 5'TOP mRNA translation through inhibition of p70s6k. EMBO J 16:3693-3704

23. Suryawan A, Nguyen HV, Bush JA, Davis TA 2001 Developmental changes in the feeding-induced activation of the insulin-signaling pathway in neonatal pigs. Am J Physiol Endocrinol Metab 281:E908-E915

24. Kimball SR, Farrell PA, Nguyen HV, Jefferson LS, Davis TA 2002 Developmental decline in components of signal transduction pathways regulating protein synthesis in pig muscle. Am J Physiol Endocrinol Metab 282:E585-E592

25. Rosen D, Miller SC, DeLeon E, Thompson AY, Bentz H, Mathews M, Adams S 1994 Systemic administration of recombinant transforming growth factor beta 2 (rTGF-beta 2) stimulates parameters of cancellous bone formation in juvenile and adult rats. Bone 15:355-359

26. McLennan IS, Koishi K 2002 The transforming growth factor-betas: multifaceted regulators of the development and maintenance of skeletal muscles, motoneurons and Schwann cells. Int J Dev Biol 46:559-567

27. Gonzalez-Cadavid NF, Bhasin S 2004 Role of myostatin in metabolism. Curr Opin Clin Nutr Metab Care 7:451-457

28. Escobar J, Van Alstine WG, Baker DH, Johnson RW 2004 Decreased protein accretion in pigs with viral and bacterial pneumonia is associated with increased myostatin expression in muscle. J Nutr 134:3047-3053

29. Patel K 1998 Follistatin. Int J Biochem Cell Biol 30:1087-1093

30. Tsuchida K 2004 Activins, myostatin and related TGF-beta family members as novel therapeutic targets for endocrine, metabolic and immune disorders. Curr Drug Targets Immune Endocr Metabol Disord 4:157-166

31. Zhang F, Laiho M 2003 On and off: proteasome and TGF-beta signaling. Exp Cell Res 291:275-281

32. Wu HH, Ivkovic S, Murray RC, Jaramillo S, Lyons KM, Johnson JE, Calof AL 2003 Autoregulation of neurogenesis by GDF11. Neuron 37:197-207

33. McPherron AC, Lawler AM, Lee SJ 1999 Regulation of anterior/posterior patterning of the axial skeleton by growth/differentiation factor 11 . Nat Genet 22:260-264 